\title{
Cardiac cachexia and muscle wasting: definition, physiopathology, and clinical consequences
}

\author{
This article was published in the following Dove Press journal: \\ Research Reports in Clinical Cardiology \\ I 3 November 2014 \\ Number of times this article has been viewed
}

\author{
Marina P Okoshi' \\ Fernando G Romeiro' \\ Paula F Martinez ${ }^{1,2}$ \\ Silvio A Oliveira $\mathrm{Jr}^{1,2}$ \\ Bertha F Polegato' \\ Katashi Okoshi' \\ Internal Medicine Department, \\ Botucatu Medical School, Sao Paulo \\ State University, UNESP, Sao Paulo, \\ Brazil; ${ }^{2}$ School of Physiotherapy, \\ Federal University of Mato Grosso \\ do Sul, Campo Grande, Brazil
}

\begin{abstract}
Cachexia and muscle wasting are frequently observed in heart failure patients. Cachexia is a predictor of reduced survival, independent of important parameters such as age, heart failure functional class, and functional capacity. Muscle and fat wasting can also predict adverse outcome during cardiac failure. Only more recently were these conditions defined in International Consensus. Considering that heart failure is an inflammatory disease, cardiac cachexia has been diagnosed by finding a body weight loss $>5 \%$, in the absence of other diseases and independent of other criteria. Muscle wasting has been defined as lean appendicular mass corrected for height squared of 2 standard deviations or more below the mean for healthy individuals between 20 years and 30 years old from the same ethnic group. The etiology of heart failure-associated cachexia and muscle wasting is multifactorial, and the underlying physiopathological mechanisms are not completely understood. The most important factors are reduced food intake, gastrointestinal alterations, immunological activation, neurohormonal abnormalities, and an imbalance between anabolic and catabolic processes. Cachexia and muscle wasting have clinical consequences in several organs and systems including the gastrointestinal and erythropoietic systems, and the heart, previously affected by the primary disease. We hope that a better understanding of the mechanisms involved in their physiopathology will allow the development of pharmacological and nonpharmacological therapies to effectively prevent and treat heart failure-induced cachexia and muscle wasting before significant body weight and muscle wasting occurs.
\end{abstract}

Keywords: heart failure, prognosis, anorexia, inflammatory activation, cardiac wasting

\section{Introduction}

Heart failure is a complex clinical syndrome in which damage to the heart or increased myocardial stress activates a systemic response that adversely affects cardiac structures and function over time. ${ }^{1}$ In the past few decades with a better understanding of heart failure physiopathology, it has become clear that pathological changes not only involve the cardiovascular system but also the renal, neuroendocrine, immune, musculoskeletal, hematological, and gastrointestinal systems, as well as nutritional state. Several studies have been performed to elucidate the physiopathology of systemic complications in heart failure and establish therapeutic measures to improve quality of life and increase survival. These include studies on heart failure-associated cachexia and muscle wasting. In this review, we present a definition, the physiopathology, and clinical consequences of cardiac cachexia and muscle wasting.

Cachexia is a strong predictive factor for reduced survival in heart failure, independent of important variables such as age, functional class, ejection fraction, and
Correspondence: Marina Politi Okosh Departamento de Clinica Medica Faculdade de Medicina de Botucatu, UNESP Rubiao Junior, S/N - CEP 18618 970, Botucatu, SP, Brazil

Tel +55 I4 3880 I I 7 I

Fax +55 I4 38822238

Email mpoliti@fmb.unesp.br 
physical capacity. ${ }^{2,3}$ The importance of cachexia in prognosis was reinforced after the description of reverse epidemiology of obesity in heart failure. In healthy individuals, increased body mass index is associated with an increased risk of developing cardiovascular disease. However, body mass index positively correlates with survival in heart failure patients. ${ }^{4,5}$ In a large meta-analysis of nine observational studies, Oreopoulus et $\mathrm{al}^{6}$ established that mortality rates from all causes and cardiovascular disease are reduced in overweight and obese heart failure patients. The mechanisms responsible for this obesity paradox in heart failure are not completely clear. ${ }^{7}$ As for cachexia, muscle wasting has been recently associated with parameters that indicate poor prognosis, such as reduced exercise capacity, muscle strength, and total peak oxygen consumption. ${ }^{8}$ Despite being known for a long time that severe body weight loss is associated with poor outcomes in several diseases, the mechanisms responsible for cachexia-induced death are not completely clear. ${ }^{9}$

\section{Definition of cachexia and muscle wasting}

Although cachexia is characterized by body weight loss and muscle wasting by a reduction in muscle mass without body weight loss, ${ }^{10,11}$ definition of these terms has evolved over time. The term "cachexia" originates from the Greek and means "bad condition". Some patients present with such intense body weight loss that cachexia diagnosis is plainly evident. However, it is often difficult to diagnose cachexia in heart failure patients, as edema increases body weight and interferes with the evaluation of other anthropometric measurements. Furthermore, it may be difficult to interpret results from nutritional biomarkers and estimate body composition through bioelectrical impedance analysis, particularly when body water is increased. ${ }^{12,13}$

Due to its influence on heart failure prognosis, it is important to have a specific simple definition of cachexia so that physicians can easily recognize the problem. However, cardiac cachexia has already had different definitions. In 1997, Anker et a $1^{14}$ proposed that, in heart failure patients, cachexia should be diagnosed when nonintentional edema-free body weight loss was $>7.5 \%$ of usual weight in the absence of hyperthyroidism or neoplastic and infectious diseases. Body weight loss should have occurred in a period longer than 6 months. Weight loss in shorter periods can also be due to heart failure, but other causes such as neoplastic or infectious diseases should be investigated. Later, the same authors observed that less intense body weight loss is already associated to worsening prognosis and proposed that a $6 \%$ body weight loss should be enough to characterize cardiac cachexia. ${ }^{15}$ In 2006, during the Cachexia Consensus Conference, ${ }^{16}$ cachexia was defined as at least $5 \%$ edema-free body weight loss in the previous 12 months (or a body mass index $<20 \mathrm{~kg} / \mathrm{m}^{2}$ ) in patients with chronic illness and at least three of the following clinical or laboratory criteria: decreased muscle strength, fatigue, anorexia, low fat-free mass index, and abnormal biochemistry characterized by increased inflammatory markers (C-reactive protein, interleukin [IL]-6), anemia ( $\mathrm{Hb}<12 \mathrm{~g} / \mathrm{dL})$, or low serum albumin $(<3.2 \mathrm{~g} / \mathrm{dL})$. It should be pointed out that cachexia differs from malnutrition or anorexia, conditions that differently from cachexia can easily be reversed with adequate nutrition. ${ }^{16}$ As heart failure is considered an inflammatory disease, cardiac cachexia has been diagnosed when body weight loss is $>5 \%$ independent of other criteria. ${ }^{17,18}$

Body weight loss leads to skeletal muscle loss and vice versa. However, isolated skeletal muscle loss can also be observed during heart failure. Chronic disease-associated muscle loss has been preferably called muscle wasting as the term "sarcopenia" usually refers to healthy age-related muscle loss. ${ }^{8}$ Differently from cachexia, muscle-wasting diagnosis depends on laboratory investigation. Dual-energy $\mathrm{X}$-ray absorptiometry has been used to accurately evaluate body composition and estimate total, lean, and fat mass. ${ }^{8,13}$ However, although expensive, computed tomography, and magnetic resonance imaging are the gold standard for muscle mass assessment. The definition of muscle wasting has recently been established as lean appendicular mass corrected for height squared of 2 or more standard deviations below the mean of healthy persons between 20 years and 30 years of age of the same ethnic group. ${ }^{19}$ Muscle wasting can also be suggested by a poor physical performance observed in different evaluation methods such as a 6-minute walk, handgrip strength, gait speed, or spiroergometry. ${ }^{13}$

\section{Epidemiology}

By defining cachexia as a body weight loss $\geq 6 \%$, Anker et a $\mathrm{l}^{15}$ observed that $34 \%$ of heart failure outpatients developed cachexia during 48 months of follow-up. Post hoc analyses of several heart failure trials have reported a prevalence of edema-free weight loss ranging from $8 \%$ to $42 \% .^{14,20}$ More recently, in optimally treated nondiabetic outpatients, cachexia (body weight loss $>5 \%$ ) was observed in $10.5 \%{ }^{17}$ Muscle-wasting prevalence has received less characterization in literature. Using the definition of muscle wasting 
mentioned earlier, this condition was recently observed in $19.5 \%$ of patients with stable chronic heart failure. ${ }^{8}$

\section{Physiopathology of heart failure-induced cachexia}

The etiology of heart failure-associated cachexia and muscle wasting is multifactorial, and the underlying physiopathological mechanisms are not completely understood. Although these mechanisms can differentially affect cachexia and muscle wasting, we present here the main factors responsible for the development of both conditions.

\section{Imbalance between anabolic and catabolic processes}

Skeletal muscle abnormalities are well established in heart failure and contribute to early dyspnea and fatigue during physical activity. ${ }^{21-23}$ Maintenance of skeletal muscle mass depends on a delicate balance between anabolic and catabolic factors. Anabolic and catabolic process imbalance has gained increasing importance in the physiopathology of heart failure-induced cachexia and muscle wasting. ${ }^{24,25}$ Enhanced proteolysis is the most consistent finding, whereas there is limited evidence for reduced protein synthesis. ${ }^{26}$ The following major proteolytic pathways can be found in skeletal muscle: lysosomal, $\mathrm{Ca}^{2+}$ dependent, caspase dependent, and ubiquitin-proteasome dependent. ${ }^{27}$ One of the most important pathways responsible for intracellular degradation of striated muscle proteins is the ubiquitin-proteasome system. ${ }^{28-30}$ During ubiquitination, damaged cytosolic proteins are linked to ubiquitin molecules and targeted toward the proteasome, where they are cleaved into short peptides and aminoacids. ${ }^{31}$

In heart failure, immunological and neurohormonal activation, as well as increased reactive oxygen species levels, stimulate nuclear factor- $\kappa \mathrm{B}$, which activates the ubiquitin proteasome system. ${ }^{13,27}$ In fact, components of the ubiquitin-proteasome system such as the muscle-specific E3 ligase muscle ring finger 1 were shown to be stimulated by proinflammatory cytokines and increased in skeletal muscle during heart failure. ${ }^{13,31}$ The ubiquitin-proteasome system can also be stimulated by myostatin and inhibited by follistatin. Myostatin modulates muscle growth by acting as a negative regulator of muscle bulk, and follistatin is a potent antagonist of myostatin. During pathological loading of the heart, the myocardium produces and secretes myostatin into circulation where it reaches skeletal muscles and inhibits their growth. ${ }^{32}$ We have observed in heart failure rats that muscle atrophy was combined with changes in myostatin/follistatin expression. ${ }^{22,33}$ Muscle disuse by bed rest can also contribute to protein catabolism. ${ }^{26}$

The most important consequence of increased protein degradation is a reduction in myocyte cross-sectional area and muscle mass, which contributes to a reduction in physical performance and daily living activities. ${ }^{21,34-38}$ As well as by increased proteolysis, reduced muscle mass can also be caused by apoptosis or necrosis. ${ }^{35,38,39}$ During several pathological conditions, muscle loss is not homogeneous and can involve predominantly slow type 1 or fast type 2 muscle fibers. ${ }^{40}$ Also in heart failure, muscle loss pattern depends on experimental model, and both a slow-to-fast and a fast-to-slow fiber-type shift has been described. ${ }^{33,41}$

Recently, Callahan and Toth ${ }^{26}$ suggested that increased proteolysis and reduced protein synthesis mainly occur during disease exacerbation and hospitalization due to increased inflammatory and neurohormonal activation. As anabolic pathways are probably insufficient to recover muscle size and function to prehospitalization levels, efforts to prevent disease exacerbation should be emphasized. ${ }^{26}$

Finally, it has been showed that increased catabolism not only occurs in skeletal muscle but also in adipose tissue. ${ }^{42,43}$

\section{Neurohormonal alterations}

During cardiac failure, neurohormonal activation is related to several deleterious cardiac and systemic effects. Heart failure patients with cachexia present increased plasma concentrations of noradrenaline, epinephrine, cortisol, and aldosterone than healthy individuals or heart failure patients without cachexia, suggesting that systemic neurohormonal activation is involved in the physiopathology of cachexia. ${ }^{2,3}$ Clinical trials have shown that angiotensin-converting enzyme inhibitors ${ }^{15}$ and $\beta$-blockers ${ }^{44}$ reduce the probability of weight loss. In in vitro studies, angiotensin II (AII), aldosterone, and catecholamines induce inflammatory cell activation and cytokine synthesis. ${ }^{45-47}$ Adrenergic stimulation may increase resting energy expenditure and induce vasoconstriction, impairing intestinal perfusion and bacterial translocation. ${ }^{27,48}$ Experimental studies have shown that AII can contribute to muscle wasting by increasing protein breakdown, reducing protein synthesis, and inhibiting muscle regenerative processes. ${ }^{28,49}$

More recently, the role of neurohormonal activation has also been evaluated in noncardiac cachexia. In liver cancer rats, $\beta$-blocker or aldosterone antagonism has increased survival and improved cancer-induced cardiac dysfunction. ${ }^{50}$

Other hormonal changes can also be involved in cachexia and muscle wasting. Heart failure patients can present a 
state of growth hormone resistance. As a consequence, insulin growth factor (IGF)-1, which stimulates protein synthesis, myoblast differentiation, and muscle growth, is decreased. ${ }^{51-53}$ IGF-1 levels can also be downregulated by AII stimulation. ${ }^{27}$ IGF-1, in turn, prevents AII-induced skeletal muscle wasting through an Akt/forkhead box O-dependent pathway. ${ }^{54} \mathrm{~N}$-terminal fragment levels of prohormone braintype natriuretic peptide (NT-proBNP), usually increased in decompensated patients, are inversely correlated with abdominal fat, suggesting that this hormone may be involved in abdominal lipolysis. ${ }^{17,43}$

\section{Immunological activation}

After the first report by Levine et $\mathrm{al}^{55}$ in 1990, showing that heart failure patients present increased tumor necrosis factor (TNF)- $\alpha$ serum levels, cardiac failure was considered as an immunologically activated disease. It was later verified in large trials such as SOLVD ${ }^{56}$ and $\mathrm{VEST}^{57}$ that TNF- $\alpha$ serum concentration is a good predictor of functional class, cardiac performance, and survival. These results were very important in understanding the physiopathology and systemic complications of heart failure. As well as TNF- $\alpha$, other inflammatory cytokines such as IL-6, the IL-1 family, and anti-inflammatory cytokines such as IL-10 are also changed in heart failure. ${ }^{27,58}$

Several cells can secrete cytokines. During heart failure, the injured myocardium and skeletal myocytes can produce and release cytokines into the circulation. ${ }^{27}$ Cytokine synthesis can be stimulated by several factors including hemodynamic overload, neurohormonal activation, tissue hypoxemia and hypoperfusion, and, as previously reported, endotoxinlike lipopolysaccharides. ${ }^{58}$ In experimental studies, increased TNF- $\alpha$ expression induces several deleterious effects; these include heart failure phenotype, endothelial dysfunction, erythropoiesis inhibition, gut permeability change, decreased free radical enzyme-removing activity, cachexia, and skeletal muscle changes such as apoptosis, proteolysis, atrophy, and functional alterations in contractile proteins. ${ }^{59-61}$ Inflammatory cytokine-induced skeletal muscle changes have important consequences on inducing muscle wasting and cachexia.

\section{Gastrointestinal abnormalities}

The role of gastrointestinal system on cardiac cachexia has recently been studied in detail. ${ }^{62}$ Several structural changes have been described such as collagen accumulation and increased thickness of the intestine wall, which suggest bowel wall edema. ${ }^{63,64}$ These alterations increase the distance between capillary wall and enterocyte membrane and can impair both intestinal mucosa perfusion and gut absorption. ${ }^{65}$ Functional changes such as reduced protein and fat absorption and increased paracellular passive permeability have also been described ${ }^{63,64}$ Additionally, increased bacteria concentration and the extent of their adherence to sigmoidal mucosal biofilm have been observed in heart failure. ${ }^{63}$ The combination of increased paracellular permeability and intestinal bacteria colonization can contribute to an increase in the gut permeability to bacterial endotoxin-like lipopolysaccharides. ${ }^{51}$ This process is known as bacterial translocation. Lipopolysaccharides are considered powerful inducers of TNF- $\alpha$ and other proinflammatory substances..$^{27,59,66}$ Finally, as hepatic abnormalities in heart failure are relatively common, they can impair the removal of bacterial endotoxins, thus contributing to immune activation. ${ }^{67}$ All these data strongly suggest that heart failure-induced gastrointestinal abnormalities are involved in systemic inflammatory activation, cachexia, and muscle wasting.

\section{Food intake reduction}

Reduced food intake can be caused by anorexia, whose causal mechanisms are not completely clear. Several factors may be involved such as poor diet palatability due to low sodium content, severe depression, and passive visceral congestion. Drugs often used in treating heart failure can contribute to reduce food intake. Angiotensin-converting enzyme inhibitors, particularly captopril, can change food taste and reduce food intake. Digitalis intoxication usually causes anorexia, nausea, and vomiting. ${ }^{51}$ Chronic and vigorous use of diuretics can deplete body potassium, reducing intestinal motility, and zinc, changing food palatability. ${ }^{34}$ Inflammatory cytokine activation and abnormal leptin and adiponectin serum levels also cause anorexia. ${ }^{68}$

Heart failure patients also experience intrinsic disturbances in appetite regulation. The hypothalamus is the main site-regulating appetite. Several neuropeptides act on different areas of the hypothalamus inducing appetite or satiety. It has been suggested in heart failure that satiety-inducing neuropeptides predominate over those leading to hunger and appetite. ${ }^{69}$ In fact, it was recently showed in mice that AII decreases food intake by suppressing hypothalamic expression of orexigenic neuropeptides. ${ }^{70}$

Other factors besides anorexia can also contribute to reduced food intake, including early satiety due to severe hepatomegaly, and reduced lipid intake, which is frequently recommended for coronary artery disease patients. A decrease in this dietary nutrient, which has a high energetic density, 
may not be compensated for by a proportional increase in carbohydrate intake. Finally, it should be pointed out that, in functional class IV patients, resting dyspnea is a limiting factor for food intake.

Finally, an increase in resting energy expenditure seems not to be involved in body weight loss during heart failure. Recent studies have shown that cachectic patients do not present with significantly increased resting energy expenditure compared with noncachectic patients and healthy controls. $^{71,72}$

\section{Clinical consequences of cachexia}

The clinical manifestations of cachexia are caused by both weight loss and systemic inflammation. In cachexia, there is a loss of tissue from three compartments: lean tissue, fat mass, and bones. ${ }^{17}$ As can be seen from the previous section, skeletal muscle wasting can be both a cause or a consequence of cachexia. ${ }^{26}$ Increased catabolism and body weight loss are also associated with a decrease in respiratory muscle strength. ${ }^{73}$

It was recently observed that fat mass wasting is also predictive of adverse outcome. It is not known whether fat loss is a surrogate of enhanced catabolism or adipose tissue is cardioprotective in the heart failure context. ${ }^{74,75}$

Severe body weight loss, even in the absence of systemic inflammation, is associated with deleterious effects in most organs and systems, including changes in cardiac and gastrointestinal systems, anemia, reduced immunity, an increased risk of acquiring infections, alterations in respiratory function, reduced bone and muscle mass, decreased capacity to urinary concentration and acidification, reduced tissue healing, and a predisposition to pressure ulcers in bed rest patients.

It is not possible to determine the cardiac consequences of heart failure-induced cachexia as the heart is primarily affected. Experimental studies have shown that cancer cachexia induces left ventricular dysfunction and molecular changes characteristic of the pathologic remodeling process. ${ }^{50,76}$ In our laboratory, we evaluated the cardiac effects of severe food restriction in normotensive and hypertensive rats. Body weight reduction was associated with a reduction in heart mass. In normotensive animals, morphological, ultrastructural, and functional myocardial changes were slight. ${ }^{77-82}$ However, in the hypertrophied heart of hypertensive rats, structural changes were more severe and were combined with ventricular and myocardial systolic dysfunction. ${ }^{83-86}$ Therefore, severe food restriction induces mild morphological and functional changes in normal hearts, which are exacerbated in hemodynamic overloaded hearts. In clinical setting, it was recently observed that left ventricular mass correlates with lean body mass in cachectic patients showing that the heart suffers similar consequences than lean tissue during cachexia. ${ }^{87}$

Cachexia can exacerbate heart failure-associated gastrointestinal changes by inducing enterocyte atrophy, reducing gut villi, and increasing the risk of bacterial translocation. ${ }^{62}$

Finally, anemia, a frequent complication of heart failure, can also be impaired by cachexia. Although anemia etiology is multifactorial, cachexia-related factors such as reduced intestinal absorption and chronic inflammation contribute to its physiopathology. Iron deficiency has been reported in variable frequency during heart failure ranging from $1 \%$ to $44 \%$, depending on case severity. ${ }^{88,89}$ Iron deficiency not only impairs erythropoiesis but also dilates the left ventricle, induces cardiac ultrastructural and mitochondrial changes, impairs cardiac function, stimulates the sympathetic nervous system, causes thrombocytosis, and impairs quality of life..$^{90,91}$

\section{Treatment perspectives}

The multifactorial pathogenesis of these conditions has complicated the development of specific therapy for heart failure-induced cachexia and muscle wasting. ${ }^{92}$ Different treatment options have been described, mostly evaluated only in experimental settings or in small clinical studies. Currently, nonpharmacological therapy as nutritional support and physical exercise is considered the basis for treating these conditions. ${ }^{93}$ It is important to point out that an increase in food intake may compensate some weight loss, but it can cause a shift in tissue distribution, particularly when muscle loss is present. $^{92}$ Therefore, nutritional support should be combined with exercise training in order to preserve or recover muscle mass. In fact, exercise training has been considered the most promising option for treating muscle wasting in several diseases. ${ }^{93}$ Table 1 shows a schematic description of potential therapeutic options for patients with cardiac cachexia and muscle wasting.

In conclusion, cardiac-associated cachexia and muscle wasting are multifactorial conditions that contribute to increased morbidity and mortality in heart failure. A better understanding of the mechanisms involved in their physiopathology will hopefully lead to the development of pharmacological and nonpharmacological therapies to effectively prevent and treat heart failure-induced cachexia and muscle wasting before significant body weight and muscle wasting occurs. 
Table I Potential clinical and experimental therapeutic approaches to counteract cardiac cachexia and muscle wasting

\begin{tabular}{llll}
\hline $\begin{array}{l}\text { Nonpharmacological } \\
\text { approaches }\end{array}$ & \multicolumn{2}{c}{ Drug therapy } & Prevention of weight loss \\
\cline { 2 - 4 } Nutrition & Anti-inflammatory substances & Appetite Stimulants & ACE inhibitors \\
Exercise & TNF- $\alpha$ inhibitory antibodies & Megestrol acetate & $\beta$-Blockers \\
& Inhibition of lipopolysaccharide bioactivity & Medroxyprogesterone acetate & \\
& Statins & Cannabinoids & \\
& Thalidomide & Anabolic steroids & \\
& Proteasome inhibitors & $\beta$-Adrenergic agonists & \\
& Other substances (pentoxifylline) & & \\
\hline
\end{tabular}

Note: Reprinted from Clin Biochem, Martins T, 47(I-2), Vitorino R, Moreira-Gonçalves D, Amado F, Duarte JA, Ferreira R, Recent insights on the molecular mechanisms and therapeutic approaches for cardiac cachexia, 8-15, Copyright (C2014, with permission from Elsevier."

Abbreviations: ACE, angiotensin-converting enzyme;TNF, tumor necrosis factor.

\section{Acknowledgments}

The authors thank FAPESP (Fundacao de Amparo a Pesquisa do Estado de Sao Paulo) (Proc No 2012/21687-1 and 2012/50512-5), CNPq(Conselho Nacional de Desenvolvimento Cientifico e Tecnologico), and UNESP (Universidade do Estado de Sao Paulo) for financial support.

\section{Disclosure}

The authors report no conflicts of interest in this work.

\section{References}

1. Greenberg B, Kahn AM. Clinical assessment of heart failure. In: Bonow RO, Mann DL, Zipes DP, Libby P, Braunwald E, editors. Braunwald's Heart Disease. A Textbook of Cardiovascular Medicine. Philadelphia: Elsevier Saunders; 2012:505-516.

2. Anker SD, Chua TP, Ponikowski P, et al. Hormonal changes and catabolic/anabolic imbalance in chronic heart failure and their importance for cardiac cachexia. Circulation. 1997;96:526-534.

3. Anker SD, Ponikowski PP, Clark AL, et al. Cytokines and neurohormones relating to body composition alterations in the wasting syndrome of chronic heart failure. Eur Heart J. 1999;20:683-693.

4. Curtis JP, Selter JG, Wang Y, et al. The obesity paradox: body mass index and outcomes in patients with heart failure. Arch Intern Med. 2005; 165:55-61.

5. Kalantar-Zadeh K, Block G, Horwich T, Fonarow GC. Reverse epidemiology of conventional cardiovascular risk factors in patients with chronic heart failure. J Am Coll Cardiol. 2004;21:1439-1444.

6. Oreopoulos A, Padwal R, Kalantar-Zadeh K, Fonarow GC, Norris CM, McAlister FA. Body mass index and mortality in heart failure: a metaanalysis. Am Heart J. 2008;156:13-22.

7. Lavie CJ, de Schutter A, Alpert MA, Mehra MR, Milani RV, Ventura HO. Obesity paradox, cachexia, frailty, and heart failure. Heart Fail Clin. 2014; 10:319-326.

8. Tacke M, Ebner N, Boschmann M, et al. Muscle wasting in patients with chronic heart failure: results from the studies investigating comorbidities aggravating heart failure (SICA-HF). Eur Heart J. 2013;34:512-519.

9. Kalantar-Zadeh K, Rhee C, Sim JJ, Stenvinkel P, Anker SD, Kovesdy CP. Why cachexia kills: examining the causality of poor outcomes in wasting conditions. J Cachexia Sarcopenia Muscle. 2013;4:89-94.

10. Letilovic T, Vrhovac R. Influence of additional criteria from a definition of cachexia on its prevalence-good or bad thing? Eur J Clin Nutr. 2013;67:797-801.

11. Martins T, Vitorino R, Moreira-Gonçalves D, Amado F, Duarte JA, Ferreira R. Recent insights on the molecular mechanisms and therapeutic approaches for cardiac cachexia. Clin Biochem. 2014;47: 8-15.
12. Oreopoulos A, Kalantar-Zadeh K, McAlister FA, et al. Comparison of direct body composition assessment methods in patients with chronic heart failure. J Card Fail. 2010;16:867-872.

13. Ebner N, Elsner S, Springer J, von Haehling S. Molecular mechanisms and treatment targets of muscle wasting and cachexia in heart failure: an overview. Curr Opin Support Palliat Care. 2014;8:15-24.

14. Anker SD, Ponikowski P, Varney S, et al. Wasting as independent risk factor of mortality in chronic heart failure. Lancet. 1997;349: 1050-1053.

15. Anker SD, Negassa A, Coats AJ, et al. Prognostic importance of weight loss in chronic heart failure and the effect of treatment with angiotensin-converting-enzyme inhibitors: an observational study. Lancet. 2003;361:1077-1083.

16. Evans WJ, Morley JE, Argiles J, et al. Cachexia: a new definition. Clin Nutr. 2008;27:793-799.

17. Christensen HM, Kistorp C, Schou M, et al. Prevalence of cachexia in chronic heart failure and characteristics of body composition and metabolic status. Endocrine. 2013;43:626-634.

18. Trullàs JC, Formiga F, Montero M, et al; RICA Investigators. Impact of weight loss on mortality in chronic heart failure: findings from the RICA registry. Int J Cardiol. 2013;168:306-311.

19. Morley JE, Abbatecola AM, Argiles JM, et al; Society on Sarcopenia, Cachexia and Wasting Disorders Trialist Workshop. The society on sarcopenia, cachexia and wasting disorders trialist workshop. Sarcopenia with limited mobility: an international consensus. J Am Med Dir Assoc. 2011;12:403-409.

20. Pocock SJ, McMurray JJ, Dobson J, et al. Weight loss and mortality risk in patients with chronic heart failure in the candesartan in heart failure: assessment of reduction in mortality and morbidity (CHARM) programme. Eur Heart J. 2008;29:2641-2650.

21. Mancini DM, Walter G, Reichek N, et al. Contribution of skeletal muscle atrophy to exercise intolerance and altered muscle metabolism in heart failure. Circulation. 1992;85:1364-1373.

22. Lima AR, Martinez PF, Okoshi K, et al. Myostatin and follistatin expression in skeletal muscles of rats with chronic heart failure. Int $J$ Exp Pathol. 2010;91:54-62.

23. Thibault R, Chanséaume S, Azarnoush K, et al. Mitochondrial protein synthesis is increased in oxidative skeletal muscles of rats with cardiac cachexia. Nutr Res. 2014;34:250-257.

24. Schulze PC. Protein catabolism and impairment of skeletal muscle insulin signalling in heart failure. Clin Sci. 2010;119:465-466.

25. Toth MJ. Impaired muscle protein anabolic response to insulin and amino acids in heart failure patients: relationship with markers of immune activation. Clin Sci. 2010;119:467-476.

26. Callahan DM, Toth MJ. Skeletal muscle protein metabolism in human heart failure. Curr Opin Clin Nutr Metab Care. 2013;16:66-71.

27. Mangner N, Matsuo Y, Schuler G, Adams V. Cachexia in chronic heart failure: endocrine determinants and treatment perspectives. Endocrine. 2013;43:253-265 
28. Yoshida T, Tabony AM, Galvez S, et al. Molecular mechanisms and signaling pathways of angiotensin II-induced muscle wasting: potential therapeutic targets for cardiac cachexia. Int J Biochem Cell Biol. 2013;45:2322-2332.

29. Cunha TF, Bacurau AV, Moreira JB, et al. Exercise training prevents oxidative stress and ubiquitin-proteasome system overactivity and reverse skeletal muscle atrophy in heart failure. PLoS One. 2012;7:e41701.

30. Foletta VC, White LJ, Larsen AE, Leger B, Russell AP. The role and regulation of mafbx/atrogin-1 and murf1 in skeletal muscle atrophy. Pflugers Arch. 2011;461:325-335

31. Gielen S, Sandri M, Kozarez I, et al. Exercise training attenuates murf-1 expression in the skeletal muscle of patients with chronic heart failure independent of age: the randomized Leipzig exercise intervention in chronic heart failure and aging catabolism study. Circulation. 2012;125:2716-2727.

32. Breitbart A, Auger-Messier M, Molkentin JD, Heineke J. Myostatin from the heart: local and systemic actions in cardiac failure and muscle wasting. Am J Physiol Heart Circ Physiol. 2011;300:H1973-H1982.

33. Damatto RL, Martinez PF, Lima AR, et al. Heart failure-induced skeletal myopathy in spontaneously hypertensive rats. Int J Cardiol. 2013;167: 698-703.

34. Anker SD, Coats AJS. Cardiac cachexia. A syndrome with impaired survival and immune and neuroendocrine activation. Chest. 1999;115 836-847.

35. Martinez PF, Okoshi K, Zornoff LA, et al. Chronic heart failure-induced skeletal muscle atrophy, necrosis, and myogenic regulatory factors changes. Med Sci Monit. 2010;16:374-383.

36. Santos DP, Okoshi K, Moreira VO, et al. Growth hormone attenuates skeletal muscle changes in experimental chronic heart failure. Growth Horm IGF Res. 2010;20:149-155.

37. Carvalho RF, Cicogna AC, Campos GE, et al. Myosin heavy chain expression and atrophy in rat skeletal muscle during transition from cardiac hypertrophy to heart failure. Int J Exp Pathol. 2003;84:201-206.

38. Von Haehling S, Steinbeck L, Doehner W, Springer J, Anker SD. Muscle wasting in heart failure: an overview. Int J Biochem Cell Biol. 2013;45:2257-2265.

39. Okutsu M, Call JA, Lira VA, et al. Extracellular superoxide dismutase ameliorates skeletal muscle abnormalities, cachexia, and exercise intolerance in mice with congestive heart failure. Circ Heart Fail. 2014;7: 519-530.

40. Ciciliot S, Rossi AC, Dyar KA, Blaauw B, Schiaffino S. Muscle type and fiber type specificity in muscle wasting. Int J Biochem Cell Biol. 2013;45:2191-2199.

41. Sullivan MJ, Green HJ, Cobb FR. Altered skeletal muscle metabolic response to exercise in chronic heart failure. Relation to skeletal muscle aerobic enzyme activity. Circulation. 1991;84:1597-1607.

42. Szabó T, Postrach E, Mähler A, et al. Increased catabolic activity in adipose tissue of patients with chronic heart failure. Eur J Heart Fail. 2013;15:1131-1137

43. Loncar G, Fulster S, von Haehling S, Popovic V. Metabolism and the heart: an overview of muscle, fat, and bone metabolism in heart failure. Int J Cardiol. 2013;162:77-85.

44. Boxall BW, Clark AL. Beta-blockers and weight change in patients with chronic heart failure. J Card Fail. 2012;18:233-237.

45. Brasier AR, Recinos AR, Eledrisi MS. Vascular inflammation and the renin-angiotensin system. Arterioscler Thromb Vasc Biol. 2002;22:1257-1266.

46. Hansen PR, Rieneck K, Bendtzen K. Spironolactone inhibits production of proinflammatory cytokines by human mononuclear cells. Immunol Lett. 2004;91:87-91

47. Werner C, Werdan K, Ponicke K, Brodde OE. Impaired beta-adrenergic control of immune function in patients with chronic heart failure: reversal by beta1-blocker treatment. Basic Res Cardiol. 2001;96:290-298.

48. Krack A, Sharma R, Figulla HR, Anker SD. The importance of the gastrointestinal system in the pathogenesis of heart failure. Eur Heart J. 2005;26:2368-2374.

49. Yoshida T, Galvez S, Tiwari S, et al. Angiotensin II inhibits satellite cell proliferation and prevents skeletal muscle regeneration. J Biol Chem. 2013;288:23823-23832.
50. Springer J, Tschirner A, Haghikia A, et al. Prevention of liver cancer cachexia-induced cardiac wasting and heart failure. Eur Heart J. 2014;35(14):932-941.

51. Invernizzi M, Carda S, Cisari C; On behalf of Societa Italiana per lo Studio Della Sarcopenia e Della Disabilita Muscolo-Scheletrica (SISDIM). Possible synergism of physical exercise and ghrelin-agonists in patients with cachexia associated with chronic heart failure. Aging Clin Exp Res. 2014;26:341-351.

52. Egerman MA, Glass DJ. Signaling pathways controlling skeletal muscle mass. Crit Rev Biochem Mol Biol. 2014;49:59-68.

53. Seiva FR, Ebaid GM, Castro AV, et al. Growth hormone and heart failure: oxidative stress and energetic metabolism in rats. Growth Horm IGF Res. 2008;18:275-283.

54. Yoshida T, Semprun-Prieto L, Sukhanov S, Delafontaine P. IGF-1 prevents Ang II-induced skeletal muscle atrophy via akt- and foxodependent inhibition of the ubiquitin ligase atrogin-1 expression. Am J Physiol Heart Circ Physiol. 2010;298:H1565.

55. Levine B, Kalman J, Mayer L, Fillit HM, Packer M. Elevated circulating levels of tumor necrosis factor in severe chronic heart failure. $N$ Engl J Med. 1990;323:236-241.

56. Torre-Amione G, Kapadia S, Benedict C, Oral H, Young JB, Mann D. Proinflammatory cytokine levels in patients with depressed left ventricular ejection fraction: a report from the studies of left ventricular dysfunction (SOLVD). J Am Coll Cardiol. 1996;27:1201-1206.

57. Deswal A, Petersen NJ, Feldman AM, Young JB, White BG, Mann DL. Cytokines and cytokine receptors in advanced heart failure: an analysis of the cytokine database from the vesnarinone trial (VEST). Circulation. 2001;103:2055-2059.

58. Yndestad A, Damas JK, Oie E, Ueland T, Gullestad L, Aukrust P. Systemic inflammation in heart failure - the whys and wherefores. Heart Fail Rev. 2006;11:83-92.

59. von Haehling S, Schefold JC, Lainscak M, Doehner W, Anker SD. Inflammatory biomarkers in heart failure revisited: much more than innocent bystanders. Heart Fail Clin. 2009;5:549-560.

60. Bozkurt B, Kribbs SB, Clubb FJ Jr, et al. Pathophysiologically relevant concentrations of tumor necrosis factor-alpha promote progressive left ventricular dysfunction and remodeling in rats. Circulation. 1998;97: 1382-1391.

61. Sivasubramanian N, Coker ML, Kurrelmeyer KM, et al. Left ventricular remodeling in transgenic mice with cardiac restricted overexpression of tumor necrosis factor. Circulation. 2001;104:826-831.

62. Romeiro FG, ZornoffLAM, Okoshi K, Okoshi MP. Gastrointestinal changes associated to heart failure. Arq Bras Cardiol. 2012;98:273-277.

63. Sandek A, Bauditz J, Swidsinski A, et al. Altered intestinal function in patients with chronic heart failure. J Am Coll Cardiol. 2007;50: 1561-1569.

64. Arutyunov GP, Kostyukevich OI, Serov RA, Rylova NV, Bylova NA. Collagen accumulation and dysfunctional mucosal barrier of the small intestine in patients with chronic heart failure. Int J Cardiol. 2008;125:240-245.

65. Krack A, Richartz BM, Gastmann A, et al. Studies on intragastric pco2 at rest and during exercise as a marker of intestinal perfusion in patients with chronic heart failure. Eur J Heart Fail. 2004;6:403-407.

66. Wrigley BJ, Lip GYH, Shantsila E. The role of monocytes and inflammation in the pathophysiology of heart failure. Eur $J$ Heart Fail. 2011;13:1161-1171.

67. Valentova M, von Haehling S, Doehner W, Murın J, Anker SD, Sandek A. Liver dysfunction and its nutritional implications in heart failure. Nutrition. 2013;29:370-378.

68. Araújo JP, Lourenço P, Rocha-Gonçalves F, Ferreira A, Bettencourt P. Adiponectin is increased in cardiac cachexia irrespective of body mass index. Eur J Heart Fail. 2009;11:567-572.

69. Von Haehling S, Lainscak M, Springer J, Anker SD. Cardiac cachexia: a systematic overview. Pharmacol Ther. 2009;121:227-252.

70. Yoshida T, Semprun-Prieto L, Wainford RD, Sukhanov S, Kapusta DR, Delafontaine P. Angiotensin II reduces food intake by altering orexigenic neuropeptide expression in the mouse hypothalamus. Endocrinology. 2012;153:1411-1420. 
71. Toth MJ, Gottlieb SS, Goran MI, Fisher ML, Poehlman ET. Daily energy expenditure in free-living heart failure patients. Am J Physiol. 1997;272:E469-E475.

72. Tacke M, Ebner N, Boschmann M, et al. Resting energy expenditure and the effects of muscle wasting in patients with chronic heart failure: results from the studies investigating comorbidities aggravating heart failure (SICA-HF). J Am Med Dir Assoc. 2013;14:837-841.

73. Habedank D, Meyer FJ, Hetzer R, Anker SD, Ewert R. Relation of respiratory muscle strength, cachexia and survival in severe heart failure. J Cachexia Sarcopenia Muscle. 2013;4:277-285.

74. Melenovsky V, Kotrc M, Borlaug BA, et al. Relationships between right ventricular function, body composition, and prognosis in advanced heart failure. J Am Coll Cardiol. 2013;62:1660-1670.

75. Lavie CJ, Osman AF, Milani RV, Mehra MR. Body composition and prognosis in chronic systolic heart failure: the obesity paradox. Am J Cardiol. 2003;91:891-894.

76. Tian M, Asp ML, Nishijima Y, Belury MA. Evidence for cardiac atrophic remodeling in cancer-induced cachexia in mice. Int J Oncol. 2011;39:1321-1326.

77. Okoshi MP, Okoshi K, Pai VD, Pai-Silva MD, Matsubara LS, Cicogna AC. Mechanical, biochemical, and morphological changes in the heart from chronic food restricted rats. Can J Physiol Pharmacol. 2001;79: 754-760.

78. Okoshi K, Matsubara LS, Okoshi MP, et al. Food restriction-induced myocardial dysfunction demonstrated by the combination of in vivo and in vitro studies. Nutr Res. 2002;22:1353-1364.

79. Cicogna AC, Padovani CR, Okoshi K, Matsubara LS, Aragon FF, Okoshi MP. The influence of temporal food restriction on the performance of isolated cardiac muscle. Nutr Res. 2001;21:639-648.

80. Fioretto JR, Queiroz SS, Padovani CR, Matsubara LS, Okoshi K, Matsubara BB. Ventricular remodeling and diastolic myocardial dysfunction in rats submitted to protein-calorie malnutrition. Am J Physiol. 2002;282:H1327-H1333.

81. Sugizaki MM, Carvalho RF, Aragon FF, et al. Myocardial dysfunction induced by food restriction is related to morphological damage in normotensive middle-aged rats. J Biomed Sci. 2005;12:641-649.
82. Gut AL, Okoshi MP, Padovani CR, Aragon FF, Cicogna AC. Myocardial dysfunction induced by food restriction is related to calcium cycling and beta-adrenergic system changes. Nutr Res. 2003;23: 911-919.

83. Okoshi MP, Okoshi K, Matsubara LS, et al. Myocardial remodeling and dysfunction are induced by chronic food restriction in spontaneously hypertensive rats. Nutr Res. 2006;26:567-572.

84. Okoshi K, Fioretto JR, Okoshi MP, et al. Food restriction induces in vivo ventricular dysfunction in spontaneously hypertensive rats without impairment of in vitro myocardial contractility. Braz J Med Biol Res. 2004;37:607-613.

85. Cicogna AC, Padovani CR, Okoshi K, Aragon FF, Okoshi MP. Myocardial function during chronic food restriction in isolated hypertrophied cardiac muscle. Am J Med Sci. 2000;320:244-248.

86. Gut AL, Sugizaki MM, Okoshi MP, et al. Food restriction impairs myocardial inotropic response to calcium and beta-adrenergic stimulation in spontaneously hypertensive rats. Nutr Res. 2008;28:722-727.

87. Molfino A, Papa A, Gasperini-Zacco ML, et al. Left ventricular mass correlates with lean body mass in patients with disease-associated wasting. J Cachexia Sarcopenia Muscle. 2014;5:251-252.

88. Nanas JN, Matsouka C, Karageorgopoulos D, et al. Etiology of anemia in patients with advanced heart failure. $\mathrm{J} \mathrm{Am} \mathrm{Coll} \mathrm{Cardiol.}$ 2006;48:2485-2489.

89. Arora NP, Ghali JK. Anemia and iron deficiency in heart failure. Heart Fail Clin. 2014;10:281-294.

90. Jankowska EA, Ponikowski P. Molecular changes in myocardium in the course of anemia or iron deficiency. Heart Fail Clin. 2010;6: 295-304.

91. Enjuanes C, Klip IT, Bruguera J, et al. Iron deficiency and health-related quality of life in chronic heart failure: results from a multicenter European study. Int J Cardiol. 2014;174:268-275.

92. Ebner N, Springer J, Kalantar-Zadeh K, et al. Mechanism and novel therapeutic approaches to wasting in chronic disease. Maturitas. 2013;75:199-206

93. Lenk K, Schuler G, Adams V. Skeletal muscle wasting in cachexia and sarcopenia: molecular pathophysiology and impact of exercise training. J Cachexia Sarcopenia Muscle. 2010;1:9-21.
Research Reports in Clinical Cardiology

\section{Publish your work in this journal}

Research Reports in Clinical Cardiology is an international, peerreviewed, open access journal publishing original research, reports, editorials, reviews and commentaries on all areas of cardiology in the clinic and laboratory. The manuscript management system is completely online and includes a very quick and fair peer-review system.

\section{Dovepress}

Visit http://www.dovepress.com/testimonials.php to read real quotes from published authors. 